\title{
EVALUATION THE EFFICACY OF PULSED RADIOFREQUENCY ( PULSED DOSE MODE) FOR THORACIC POST HERPETIC NEURALGIA TREATMENT
}

\author{
Mohamed E. Abdel Shafi MD, FIPP \\ Department of anesthesiology and Intensive Care, Faculty of Medicine Zagazig University
}

\begin{abstract}
Neuralgia is a sharp, shocking pain that follows the pathway of a nerve and is due to irritation or damage to the nerve. Post-herpetic neuralgia (PHN) is one of the most common forms of neuralgia . It is characterized by persisting pain in the affected dermatome after rash healing which last for years. PHN is often resistant to the traditional methods of treatment. Pulsed Radiofrequency (PRF) is known as an effective treatment for neuropathic pain. The aim of this study was to evaluate the efficacy of PRF ( pulsed dose response second generation of pulsed radiofrequency) for the management of PHN .

This study included 20 patients who have post herpetic neuralgia in thoracic dermatomes, the patients were selected according to inclusion and exclusion criteria, A $10 \mathrm{~cm}$ length cannula with $10 \mathrm{~mm}$ active tip was introduced in the thoracic transforaminal opening of the affected dermatomes under fluoroscopic guidance to become adjacent to dorsal root ganglia (DRG), this position was confirmed by sensory and motor stimulation, after obtaining the appropriate stimulation, PRF was applied to the corresponding level( temperature 42 degree, pulse number 900, voltage 65 ), after finishing the procedure the patients were evaluated at one, three and six months using McGill questionnaire.

The result of this study demonstrated that there are highly statistically significant decreases in Pain Rating Index (PRI) and Pain Persistent Intensity (PPI) in all patients of McGill pain questionnaire at one, three or six months after radiofrequency application, when compared with before radiofrequency application. In conclusion, the use of PRF for treatment of $\mathrm{PHN}$ is a safe therapeutic alternative method. Benefits include that the procedure is minimally invasive, provides short-term pain relief and improves quality of life.
\end{abstract}

Keywords: Postherpatic neuralgia; Pulsed radiofrequency

How effective $\&$ do study to evaluate efficacy...change $1^{\text {st }}$ sentence .

\section{INTRODUCTION}

$\mathbf{H}$ erpes Zoster (HZ) or shingles is considered one of the common diseases its incidence varying from 2.2 to 3.4 per 1000 person|year(1). In high percentage of the patients, in the most cases healing of the skin and disappearance of the pain occur within 3-4 weeks. However, after rash was healed the pain may go on and this situation known as post herpetic neuralgia ( PHN) (2).

PHN affects $50 \%$ of patients over 60 years of age and $15 \%$ of anti herpetic patients. The pain of PHN spreadsthrough the single nerve root from the central dorsal line in a ventral direction, harmonious with the dermatomal rash (3).

This chronic neuropathic pain is associated with a decline in quality of $\backslash$ life and daily fluctuations in stress and negative mood that can worsen the experience of neuropathic pain.(4)

The treatment methods are intricate and largely depend on the type and particularity of pain described by the patient.(5)

As there is no standard treatment accessible for PHN , accordingly there are multiple therapies recommended (3). Most of the treatment depends on the use of psychotropic and anticonvulsant medications (6). Pharmacological therapies were influential in reducing pain intensity and improved quality of life in managing PHN. It include tramadol, opioid analgesics, anticonvulsant drugs, tricyclic antidepressant drugs , and topical agents. (7).There are many different techniques that were used in treatment of pain like nerve blocks, subarachnoid injection of local anesthetics, removal of the affected skin and neuromodulation techniques (8) Pulsed radiofrequency ( PRF) is a different therapeutic strategy that has been used by pain practitioners as a non- or minimally neurodestructive technique where short burst of high frequency current are applied to nervous tissue (9). The basic principles of radiofrequency (RF) involve transferring an alternating electrical current, in the same frequency range as radio waves by a generator to a nerve via an active electrode (10).The most common site of PHN is the thoracic nerve (T1-12) with an incidence of up to $50 \%$ (11). As the dorsal root ganglion (DRG) neurons are responsible for pain so it is the most common targets of PRF treatment. PRF is used to treat these painful neuralgia conditions by interrupting sensory nerves which carry pain signals, a process known as lesioning with results lasting an average of 6-9 months (12) .This study hypothesized that the use of PRF for the treatment of PHN may cause pain relief for longer periods than the other traditional methods - A previous study found that the use of PRF is safe and highly effective treatment for neuropathic pain of different causes (13). However, other study showed that the use of PRF in treatment of PHN is limited (14). 
The aim of this study was to evaluate the efficacy of PRF ( pulsed dose response second generation of pulsed radiofrequency) for the management of $\mathrm{PHN}$ in one group clinical trial at one, three and six months .

\section{PATIENTS AND METHODS}

This prospective cohort study was performed at pain unit of Zagazig University Hospitals. After approval from local Ethics Committee and obtaining a written informed consent from twenty patients who have postherpatic neuralgia in the thoracic dermatomes .

\section{Inclusion criteria}

1 - Duration of pain more than 6 months and failure to respond to medical treatment

2 -Patients has positive diagnostic block by $1 \%$ xylocaine ( thoracic transforaminal injection of the affected root) in the operating room and under fluoroscopic guidance.

\section{Exclusion criteria}

1 - Patients with polynuropathy and other neurological problem.

2- Bleeding tendency

3-Severe systemic disorder and severe immunocompromised patients

4- Major psychopathology.

Firstly, the therapeutic area was detected by the thoracic segment which affected by $\mathrm{HZ}$ and accompanied with specific neuropathic pain. Patients were placed in prone in the surgical bed with suitable pillow under the chest .

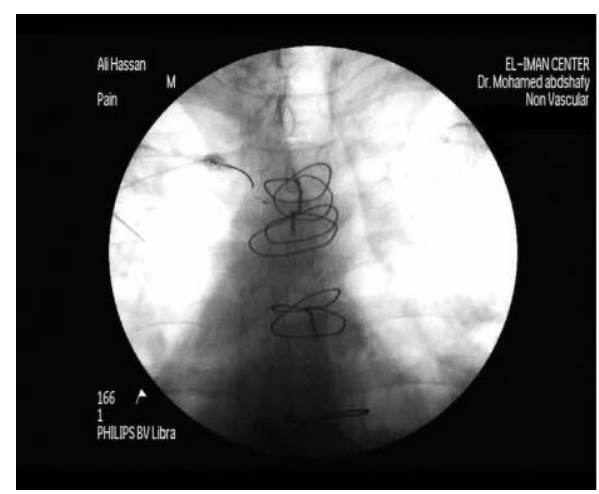

Fig 2 :oplique view show the RF cannula inside T2foramen
A $10-\mathrm{cm}$ electrode with $10 \mathrm{~mm}$ active tip (20G cosman cannula RFK TM ; Cosman INC. Burlington, MA), we insert needle under fluoroscopic guidance, the aim is to enter the intervertebral foramen adjacent to DRG, this position was confirmed by sensory stimulation to produce tingling, numbness of the affected nerve using the following parameters ( frequency ;50HZ , pulse width; 1 $\mathrm{ms}$, voltage; $0.4 \mathrm{v}-0.6 \mathrm{v})$. after gaining the convenient stimulation, PRF ( pulsed dose mode) was applied 900 pulse at corresponding level to 42 degree, voltage 65 .

After one month of the procedure, we started to decrease the dose of medical therapy to avoid the phase of post procedure discomfort (the phase in which the patient may feel neuritis like effect which may last for up to three weeks ) after using the machine.

Pain was evaluated 1,3,6 months after the procedure using McGill pain Questionnaire Referance. The used drugs were maintained or reduced according to pain relief and any complication occurred during the procedure were recorded. We use radiofrequency machine ( neurotherm NT 1100 \{RDG medical, croydon, $\mathrm{UK}\}$ ) and we use pulsed dose response second generation of pulsed RF

Sample size: According to percentage of improvement and at $80 \%$ power and $95 \%$ confidence interval the estimated sample size was 20 patients

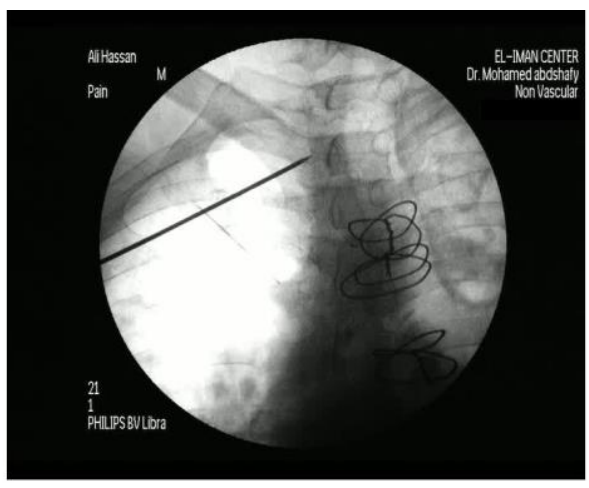

Fig1:oplique view detection of $\mathrm{T} 2$ foramen before introducing of RF cannula 


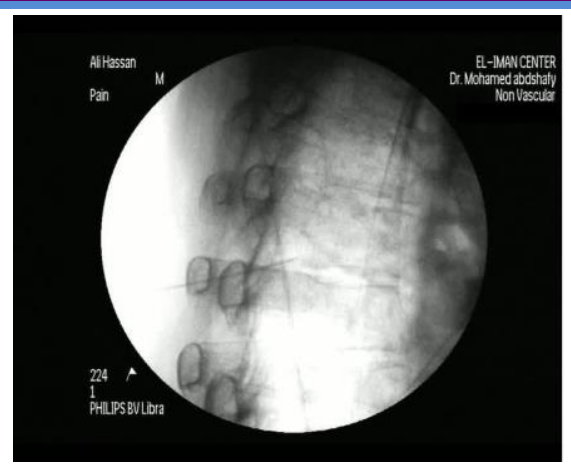

Fig 3;lateral view show the RFcannula inside T2 foramen

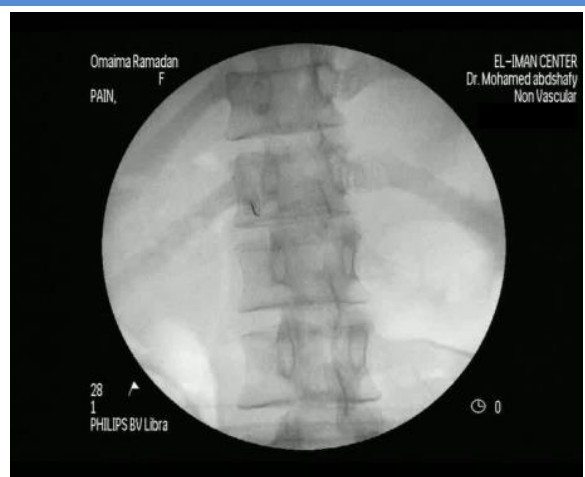

Fig 4 :oplique view show the RF cannula inside T12foramen

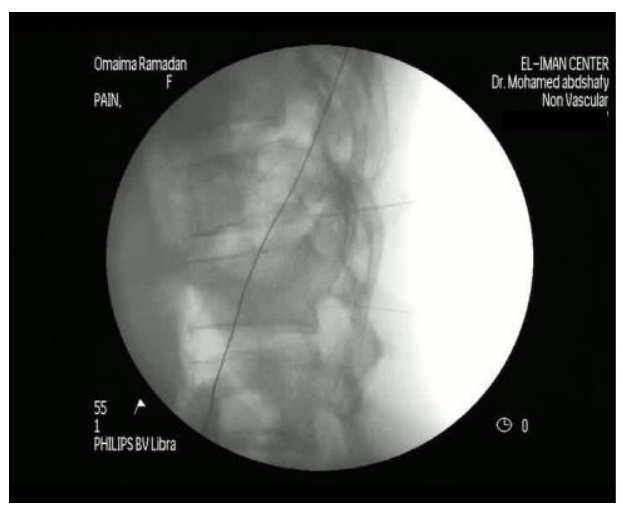

F5; lateral view show the RFcannula inside T12 foramen

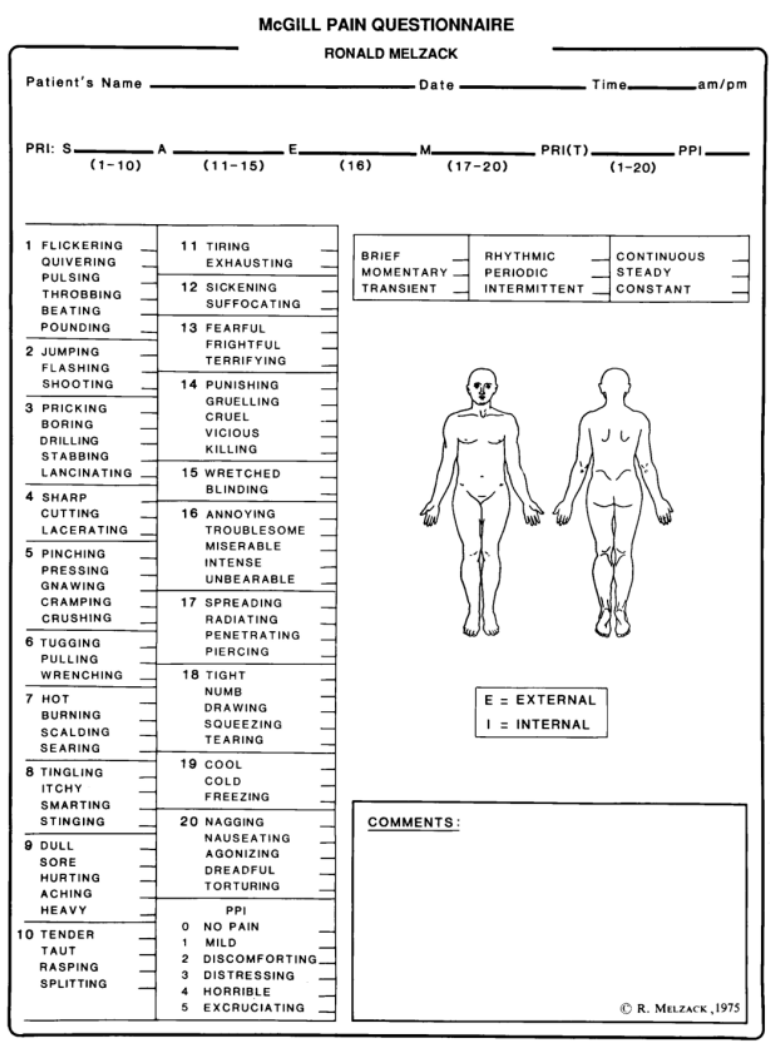

McGill pain Questionnaire 


\section{Statistical analysis:}

The data were collected, presented and analyzed using SPSS-PC (version 20) software. Comparisons between several measures of PRI (Mean \pm SD) were done using one way ANOVA test and paired t-test to measure change from baseline . Also, changes in categorical variables were done by Mc Nemar $\mathrm{s}$ ch $-\mathrm{i}$ squared test

Correlation coefficient was calculated to determine correlation of age and sex to pain Rating Index scores before and after radiofrequency. The test results were considered significant when P.value $<0.05$.

\section{RESULTS}

Twenty patients were initially enrolled in this study, although only nineteen patients successfully completed the entire study. One patient was withdrawn because of failure to complete all the postoperative evaluations Table (1): Relevant Characteristics of the Studied Cases (19 cases)

\begin{tabular}{ll}
\hline \multirow{2}{*}{ AGE year } & Studied Group \\
\cline { 2 - 2 } & $\mathbf{N}(\mathbf{1 9 )}$ \\
\hline mean $\pm(\mathrm{SD})$ & $57.95(9.59)$ \\
Median & 57 \\
Range & $42-72$ \\
\hline SEX Number $(\%)$ & $7(36.8)$ \\
Male Number $(\%)$ & $12(63.2)$ \\
Female Nutio & $1 / 1.7$ \\
M/F Ratio & \\
\hline
\end{tabular}

Table (2): Difference in the Mean (SD0) scores of Pain Rating Index (PRI) of postherpetic neuralgia before radiofrequency and (one, three, six) Months after radiofrequey

\begin{tabular}{llllll}
\hline $\begin{array}{l}\text { Characteristics } \\
\text { Pain Rating Index }\end{array}$ & \multicolumn{2}{c}{ Radiofrequency application } & \multicolumn{2}{c}{ P-value } \\
\cline { 2 - 5 } & Before & $\begin{array}{l}\text { 1 month } \\
\text { after }\end{array}$ & $\begin{array}{l}\mathbf{3} \text { month } \\
\text { after }\end{array}$ & $\begin{array}{l}\mathbf{6} \text { month } \\
\text { after }\end{array}$ & \\
\hline $\mathrm{n}$ & 19 & 19 & 19 & 19 & \\
mean $\pm(\mathrm{SD})$ & $41.6(7.2)^{* *}$ & $32.1(8.1)$ & $23.7(9.3)$ & $18.1(9.9)$ & $<0.001$ \\
Median & $44 * *$ & 33 & 23 & 15 & \\
Min-max & $24-52^{* *}$ & $17-47$ & $8-47$ & $4-41$ & \\
\hline
\end{tabular}

**There is a highly statistical significant differences between Mean scores of Pain Rating Index (PRI) of post herpetic neuralgia before radiofrequency and (one, three, six) months after radiofrequency using paired t-test

$* * \mathrm{p}<0.001$ when compared with baseline

Table (3): Difference in the Mean scores(SD) of Pain Rating Index (PRI) of postherpetic neuralgia before radiofrequency and (one, three, six)

Months after radiofrequency

\begin{tabular}{|c|c|c|c|c|}
\hline & $\begin{array}{l}\text { Pain } \\
\text { Index }\end{array}$ & Rating & $\begin{array}{l}\text { Paired } \\
\text { test }\end{array}$ & t P-value \\
\hline & Mean & SD & & \\
\hline $\begin{array}{l}\text { Before Radiofrequency } \\
\text { Vs }\end{array}$ & 41.6 & 7.2 & 6.6 & $<0.001^{*}$ \\
\hline 1 Month after Radiofrequency & 32.1 & 8.1 & & \\
\hline $\begin{array}{l}1 \text { Month after Radiofrequency } \\
\text { Vs }\end{array}$ & 32.1 & 8.1 & 6.1 & $<0.001^{*}$ \\
\hline 3 Months after Radiofrequency & 23.7 & 9.3 & & \\
\hline $\begin{array}{l}3 \text { Months after Radiofrequency } \\
\text { Vs }\end{array}$ & 23.7 & 9.3 & 6.7 & $<0.001^{*}$ \\
\hline 6 Months after Radiofrequency & 18.1 & 9.9 & & \\
\hline
\end{tabular}

** There is a highly statistical significant difference between Mean scores 
of Pain Rating Index (PRI) of postherpetic neuralgia (before radiofrequency and one month), (one and three months after radiofrequency ) and (three and six months after radiofrequency)

Table (4): Difference in the Persistent Pain Intensity (PPI) of postherpetic neuralgia before radiofrequency and (one, three, six) months after radiofrequency

$\begin{array}{lll}\text { Characteristics } & \text { Radiofrequency application } & \text { Mc Nemar P-value } \\ & \text { on } 19 \text { studied cases } & \text { s chi- }\end{array}$

\begin{tabular}{|c|c|c|c|c|c|c|c|c|c|c|}
\hline \multirow[b]{2}{*}{ PPI } & \multicolumn{2}{|c|}{ Before } & \multicolumn{2}{|c|}{$\begin{array}{l}1 \text { month } \\
\text { after }\end{array}$} & \multicolumn{2}{|c|}{$\begin{array}{l}3 \text { month } \\
\text { after }\end{array}$} & \multicolumn{2}{|c|}{$\begin{array}{l}6 \text { month } \\
\text { after }\end{array}$} & \multirow{7}{*}{$42.21 * *$} & \multirow{7}{*}{$<0.001$} \\
\hline & $\mathbf{N}$ & $\%$ & $\mathbf{N}$ & $\%$ & $\mathbf{N}$ & $\%$ & $\mathbf{N}$ & $\%$ & & \\
\hline 0 & 0 & 0 & 0 & 0 & 0 & 0 & 2 & 10.5 & & \\
\hline 1 & 0 & 0 & 0 & 0 & 5 & 26.3 & 7 & 36.8 & & \\
\hline 2 & 1 & 5.3 & 7 & 36.8 & 8 & 42.1 & 6 & 31.6 & & \\
\hline 3 & 7 & 36.8 & 8 & 42.1 & 5 & 26.3 & 3 & 15.8 & & \\
\hline 4 & 11 & 57.9 & 4 & 21.1 & 1 & 5.3 & 1 & 5.3 & & \\
\hline
\end{tabular}

There is a highly statistical significant difference between Persistent Pain Intensity (PPI) of postherpetic neuralgia before radiofrequency and ( one, three, six) months after radiofrequency.

Table (5) : Correlation between ( Age, Sex ) and Pain Rating Index score (PRI) of postherpetic neuralgia before radiofrequency and six months after radiofrequency.

\begin{tabular}{lcc}
\hline Characteristics & Correlation & P-value \\
Coefficient & $(r)$ & $(r)$
\end{tabular}

Pearson correlation between age and PRI

$\begin{array}{lll}\text { PRI before radiofrequency with Age } & 0.625 & 0.004 * *\end{array}$

\begin{tabular}{llc}
\hline PRI 6 months after radiofrequency with Age & 0.646 & $0.003^{* * *}$ \\
\hline Improvement in PRI after radiofrequency with Age & -0.327 & 0.171 \\
\hline Spearman s correlation between sex and PRI & & 0.456 \\
PRI before radiofrequency with Sex & -0.182 & 0.388 \\
\hline PRI 6 months after radiofrequency with Sex & -0.21 & 0.714 \\
\hline Improvement in PRI after radiofrequency with Sex & 0.09 & 09 \\
\hline
\end{tabular}

** There is a highly statistical significant positive correlation between Age and (PRI) score of postherpetic neuralgia before radiofrequency and six months after radiofrequency. While improvement in PRI score does not show significant correlation with age. Also sex show no significant correlation either with (PRI) of postherpetic neuralgia before and after radiofrequency nor with Improvement in PRI.

- There was excellent pain reduction in three patients who did not need additional pharmacological or interventional treatment, ten cases responded to PRF and needed only minimal dose of trycyclic antidepressant $(25 \mathrm{mg}$ of amitryptaline once daily), six cases showed mild respond to PRF (half of the original treatment was reduced.There is no complications were detected during the procedure.

\section{DISCUSSION}

When the intricate kind of the disease is considered, it is normal that no definitive treatment of PHN is available (3).

PRF is nondestructive procedure where current is delivered in a pulse of 20 milliseconds followed by a silent period of 480 milliseconds to avoid radiofrequency heat lesions (9).

The analgesic action of PRF is including the increase of noradrenergic and serotonergic 
descending inhibitory pathways . The long term analgesia of PRF isrelated to change in gene expression in the neurons (15).

This study examined the intermediate- term effect of procedure after one month, three and six months. It demonstrated that the pain severity gradually improved in most of the patients.

This result is in agreement with the study of Jenneifer et al (4) who reported that pulsed RF ablation of the DRG provided significant pain relief compared with conventional pain treatment in patients with intractable $\mathrm{PHN}$.

Also, Cohen et al (12) when compared treatment outcome between pharmacotherapy, PRF of the intercostals nerves and PRF of DRG in neuralgia after surgery, they reported that PRF of the DRG was highly effective than pharmacotherapy . Multiple clinical trials and animal experiments have demonstrated the superiority of PRF for management of neuropathic pain over other available clinical methods (16-17-18)

In this study there is highly statistical positive correlation between age and PRI before application of PRF.This is in accordance with David et al (3)who found that PHN affected $50 \%$ of patients over 60 years of age and $15 \%$ of anti herpetic patients.

In this study, there are several limitations

First limitation :after obtaining appropriate stimulation (proper position of the needle), PRF was preformed (900 pulses for every DRG) and there is no strict data to support this number of pulsation.

Second limitation : this mode is new and there is no adequate number of studies was done using this mode of pulsations.

Third limitation: we only observed the intermediate effect .So, long term follow up observation is needed.

In conclusion : the use of PRF for treatment PHN is a safe therapeutic alternative method. The advantage of this procedure is minimally invasive, provides short-term pain relief and improves quality of life.

\section{REFERENCES}

1. Donahue JG, Choo PW; et al: The incidence of herpes zoster. Arch intern. Med. 1995; 155: 1605-1609.

2. Dworkin RH., Portenoy RK. Pain and its persistence in herpes zoster. Pain 1996; 67: 241-251.

3. David N., Alexander M. Postherpetic neuralgia: The never -ending challenge. Pain Practice 2005:5(4):327-340.

4. Jenneifer A; Michael R; et al: pain coping strategies play a role in the persistence of pain in post - herpetic neuralgia. Pain 2003; 106: 453-460.

5 . Whitley RJ. A 70-year-old woman with shingles: Review of herpes zoster. JAMA 2009;302: 73-80.

6. Dubinsky RM, Kabbani H., et al; Practice parameter: Treatment of postherpetic neuralgia. Neurology. 2004; 63:959-965.

7. Dworkin RH, Backonja M., et al; Advances in neuropathic pain: diagnosis, mechanism, and treatment recommendations. Arcb. Neurol. 2003; 60: 1524-1534.

8. Van wijck AJ, Opstelen W., et al., The PINE study of epidural steriods and local anaesthitics to prevent postherpetic neuralgia: a randomized controlled trail. Lancet 2006; 376(9506): 219-224.

9. Cosman ER,Jr., Cosman ER, Sr, Electric and thermal field effects in tissue around radiofrequency electrodes. Pain Med 2005;6:405-424.

10.Kim Y.H.,Lee C.J.,Lee S.C.,Huh J.,Nahm F.S.,Kim H.Z. AND Lee M,K. : Effect of pulsed radiofrequency for postherpetic neuralgia Acta Anaesthesiologica Scandinavica 2008, volum 52: page 1140-1143

11.Mondelli M.,Romano C.,Della Porta P.and Rossi A. :Electrophysiological finding in peripheral fibers of subjects with and without post-herpetic neuralgia.Electroencephalogr. Clin Neurophysiol.1996;101:185-191

12 . Cohen Sp, Sireci A., Wu Cl ,Larkin TM ,Williams K A. and Hurley RW : Pulsed radiofrequency of the dorsal root ganglia is superior to pharmacotherapy or pulsed radiofrequency of the intercostal nerve in the treatment of chronic post surgical thoracic pain . pain physician 2006; 9 : 227- 236.

13. Kim YH., Lee CJ., et al: Effect of pulsed radiofrequency for postherpetic neuralgia. Acta Anaesthesiol Scand. 2008; 52: 1140-1143.

14. Guo L,Kubat NJ ,Nelson TR and Isenberg KA : Meta-analysis of clinical efficacy of pulsed radiofrequency energy treatment .Ann Sur 2012;255:457-467

15. Ma Ke, phD ,Fan Yinghui, MS, Jin Yi phD,Huang Xuehua, Ms, Liu Xiaoming, PhD, Cheng Zhijun, Ms , Huang Chao , MS and Wabg Yingwei , MD , PhD; Efficacy of pulsed radiofrequency in the treatment of thoracic postherpetic neuralgia from the angulus costae : a randomized double- blind, controlled trial. Pain physician $2013 ; 16: 15-25$.

16. Philip CN , Candido KD,Joseph NJ and Crystal GJ : Succesful treatment of meralgia paresthetica with pulsed radiofrequency of 
lateral femoral cutaneous nerve .Pain Physician 2009;12:881-885

17. Van Boxem K, Van Eerd M and Van Zundert $\mathrm{J}$ : Radiofrequency and pulsed radiofrequency treatment of chronic pain syndrome the available evidence . Pain Pract 2008 ; 8: 3385393
18. Perret DM ,Kim DS ,Li KW , Sinavsky K ,Newcomb RL, Miller JM and Luo ZD : Application of pulsed radiofrequency currents to rat dorsal root ganglia modulates nerve injury- induced tactile allodynia. Anesth Analg 2011; $113: 610-616$ 